NBER WORKING PAPER SERIES

\title{
WAITING FOR THE PAYDAY? THE MARKET FOR STARTUPS AND THE TIMING OF ENTREPRENEURIAL EXIT
}

\author{
Ashish Arora \\ Andrea Fosfuri \\ Thomas Roende \\ Working Paper 24350 \\ http://www.nber.org/papers/w24350 \\ NATIONAL BUREAU OF ECONOMIC RESEARCH \\ 1050 Massachusetts Avenue \\ Cambridge, MA 02138 \\ February 2018
}

We thank seminar participants at Fuqua School of Business, Copenhagen Business School, Carlos III University, Danish Technical University, University of Tübingen, University of Mannheim, University of Southern California, KAIST, and the 6th HEC Paris Workshop on Entrepreneurship, for comments and suggestions. An earlier draft was circulated with the title "Investment in absorptive capacity and the decision between going early and waiting in the market for technology". The views expressed herein are those of the authors and do not necessarily reflect the views of the National Bureau of Economic Research.

NBER working papers are circulated for discussion and comment purposes. They have not been peer-reviewed or been subject to the review by the NBER Board of Directors that accompanies official NBER publications.

(C) 2018 by Ashish Arora, Andrea Fosfuri, and Thomas Roende. All rights reserved. Short sections of text, not to exceed two paragraphs, may be quoted without explicit permission provided that full credit, including $(\odot$ notice, is given to the source. 
Waiting for the Payday? The Market for Startups and the Timing of Entrepreneurial Exit Ashish Arora, Andrea Fosfuri, and Thomas Roende

NBER Working Paper No. 24350

February 2018

JEL No. L26,O34

\begin{abstract}
$\underline{\text { ABSTRACT }}$
Most technology startups are set up for exit through acquisition by large corporations. In choosing when to sell, startups face a tradeoff. Early acquisition reduces execution errors but later acquisition improves the likelihood of finding a better match since in the early market, there are fewer buyers because early acquisition requires costly absorptive capacity. Moreover, the buyer's decision to invest in absorptive capacity is related to the startup's decision about the timing of the exit sale. In this paper, we build a model to capture this complexity and the related tradeoffs. We find that the early market for startups is inefficiently thin if the timing of exit is a strategic choice, i.e. startups have to commit to whether to exit early or late. Too few startups are sold early, and too few buyers invest in absorptive capacity. Paradoxically, venture capital aggravates the inefficiency. However, if the timing of exit is a tactical choice, i.e. startups can choose to go late after observing the early offers, there are too many early acquisitions and too much investment in absorptive capacity by incumbents
\end{abstract}

Ashish Arora

Fuqua School of Business

Duke University

Box 90120

Durham, NC 27708-0120

and NBER

ashish.arora@duke.edu

Andrea Fosfuri

Bocconi University

andrea.fosfuri@unibocconi.it
Thomas Roende

Copenhagen Business School

Department of Innovation and

Organizational Economics

DK-2000 Frederiksberg, Denmark

thr.ino@cbs.dk 


\section{Introduction}

Many inventions begin the journey to commercialization in startups. After a period of incubation and development, the invention can be passed on to an incumbent, typically by the incumbent buying the startup. ${ }^{1}$ When to sell a startups is an important decision for entrepreneurs and investors. There are natural inflection points in the lifecycles of startups when they can be acquired or can choose to persist and develop the technology closer to commercialization (Graebner and Eisenhardt, 2004; Allain et al. 2016). As venture capitalist, Bill Janeway from Warburg Pincus, writes ${ }^{2}$

Given the much extended path to self-sustaining positive cash flow from operations, the responsible entrepreneur and VC are charged with asking themselves the same question at each step along the way:

- The technology does "light up"-do we sell now?

- We have three credible customers who will testify that they have bought our offering and will buy more-do we sell now?

- We have access to another round of capital but it will be dilutive and Business Risk looms-do we sell now?

It is not difficult to find other examples. Foursquare, a local search-and-discovery service mobile app based in New York City, was offered $\$ 100$ million by both Yahoo and Facebook, one year after it launched in 2010, and both offers were turned down. Receptos, a San Diego-based biotechnology company, waited seven years after its foundation before accepting a multibillion offer from Calgene, which outbid AstraZeneca, Teva and Gilead. While both Foursquare and Receptos seem to have made the right decision in postponing their exit, the counterfactual is unclear. Failure rates among technology startups are extremely high. ${ }^{3}$ For instance, Maine and Thomas (2017) provide the example of an MIT startup, BIND, which raised several rounds of capital to apply its nano-particle drug delivery to new therapies. Despite going public via an IPO in 2013, in 2016, it was forced to file for bankruptcy following a failed clinical trial. BIND was acquired by Pfizer shortly thereafter for its intellectual property assets.

\footnotetext{
${ }^{1}$ The National Venture Capital Association reports that acquisitions accounted for $82 \%$ of the venture capital-backed exits in 2016 in the US (https://nvca.org/pressreleases/2017-nvca-yearbook-highlightsbusy-year-venture-industry-nvca/). Cunningham (2017) shows that out of the 83 startups in the US medical device industry that exited, 71 were acquired. Mathisen and Rasmussen (2016) also identify acquisitions as the most frequent exit strategy in the case of successful Norwegian startups.

${ }^{2}$ William Janeway, Warburg Pincus. https://medium.com/the-wtf-economy/enterprise-software-deathand-transfiguration-99eb1d3fc4c0

${ }^{3}$ Startup failure rates are as high as $90 \%$ in some industries. Remarkably, the probabilities of success of biotech companies' in stage III of drug development are lower than the those of large pharmaceutical firms in comparable conditions (Guedj and Scharfstein, 2004; Arora et al., 2009).
} 
Arguably, BIND would have been better off being acquired at an earlier stage rather than investing in building an organization and clinical trials.

Figure 1 shows the timing of startup sales across three different industries: bio-pharma, software and mobile devices. ${ }^{4}$ It plots the respective fractions of startups acquired before round A, before round B and after round B. It shows that there is heterogeneity within as well as across industries in the timing of startup sales, with a higher share of late acquisitions in bio-pharma. Insofar as development costs in biotech typically are higher than in software, financial constraints on startups are unlikely to be the main determinant of exit timing; other forces are likely to be at work.

Figure 1: Timing of acquisitions of startups, 1990-2015, by sector.

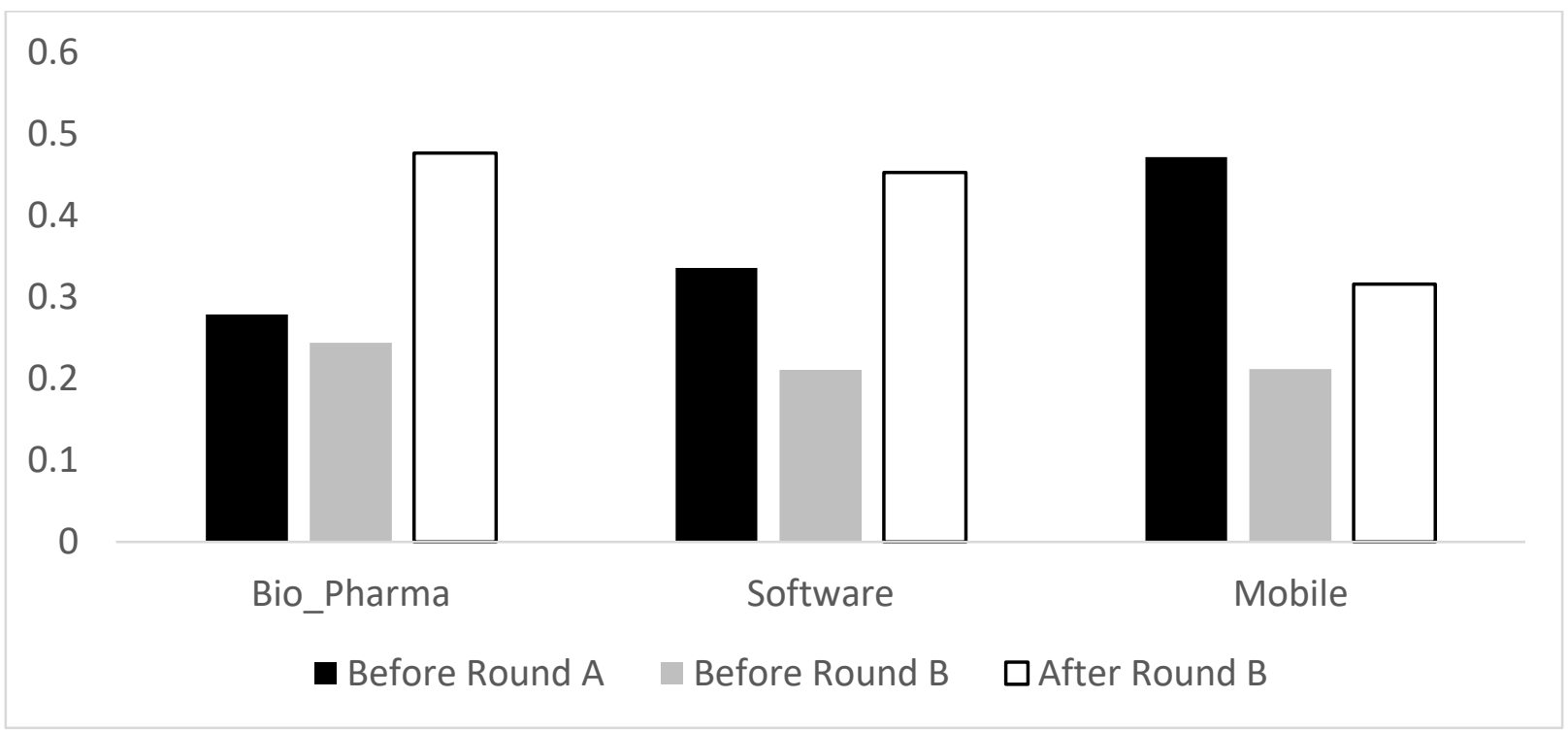

Source: Authors' calculation based on Crunchbase.

In this paper, we build a model to understand the factors that explain the timing of startup sales, and to investigate the efficiency properties of the equilibrium between buyers and sellers. We focus on exit through acquisition by an incumbent, which is by far the most common exit route for successful startups. ${ }^{5}$ The timing of the acquisition is important for understanding the division of innovative labor (Arora and

\footnotetext{
${ }^{4}$ Figure 1 is based on Crunchbase data for 1990-2015. We consider only startups which were acquired. Firms acquired before any institutional investment are classified as before Round A.

${ }^{5}$ Formally, we ignore IPOs. However, as discussed below, our analysis could be extended to allow for an IPO as a possible further stage if the startup is not acquired.
} 
Gambardella, 1994). ${ }^{6}$ If innovation is the outcome of mutual specialization between startups that develop inventions, and established incumbents that will eventually commercialize most of them (Arora et al., 2001; Gans and Stern, 2003), our paper analyzes one way in which the market for startups that underpins the division of innovative labor may be inefficient.

In studying the timing of the startup sale, we focus on the tradeoff between execution errors and the possibility of a better match. On the one hand, startups are often less efficient at developing inventions. To anticipate our model, startups have a greater likelihood of failing even if the underlying technology is good. For instance, they may not hire the right people, they may develop the product for the wrong market, or try to develop it for too many markets and succeed at none, or they may simply run out of money. Established firms have developed routines for developing and commercializing inventions, which are less prone to execution failures. These firms already possess product development processes, manufacturing capability, sales and marketing channels, logistics and distribution, and other complementary resources (Teece, 1986) which startups have to create from scratch. ${ }^{7}$ Mistakes and missteps are inevitable. On the other hand, early stage markets tend to have fewer buyers than later stage markets. If the value created by a startup is idiosyncratic to a buyer, having more potential buyers increases the total value. This creates a tradeoff for the startup: Create and capture more value by being acquired when the business is more mature but run a greater risk of failing due to poorer execution.

The other important player in this process is the potential buyer. Buying early stage startups requires absorptive capacity - the ability to evaluate the technology and the ability to develop the nascent technology and to use it (Cohen and Levinthal, 1989). Buyers may have to be structured differently to absorb nascent startups, compared to later-stage startups with more mature organizations and technology (Arora et al., 2014). Naturally, startups wishing to sell at an early stage will do better when there are more early stage buyers and vice versa.

In our model, a crucial determinant of the market outcome is whether startups have to make a strategic choice between going early versus late. Flexibility inevitably will result in greater information leakage and loss of control over the invention (e.g. Gans et al. 2016). If such information leakages destroy value, the startup must choose between selling early, or remaining in stealth mode till it is more mature. ${ }^{8}$

\footnotetext{
${ }^{6}$ Arora et al. (2016) show that nearly $50 \%$ of US manufacturing firms that introduced an innovative product between 2007 and 2009 obtained the invention externally, and that startups were disproportionately important as sources of invention.

${ }^{7}$ Åstebro and Serrano (2015) also document the importance of access to complementary assets. If a startup partners with an incumbent firm with complementary assets, they find that the probability of commercialization doubles, and that expected revenues increase by $29 \%$, at the sample mean. ${ }^{8}$ Gans et al. (2016) argue that entrepreneurship implies choosing between alternatives, and that, once the choice is made, some options will be extinguished. Indeed, many venture capitalists advise startups to
} 
Startups also may have to commit to exiting late if they are required to make large sunk investments that are valuable only to later acquirers. ${ }^{9}$ However, if a startup that enters the early market has the option to reject all early offers and wait for the late market, its exit timing is a tactical choice. The outcomes in these two cases differ in important ways.

We start by assuming that a startup has no flexibility, and has to choose between going early or late. We find that the number of buyers that invest in absorptive capacity, and the probability of the startup selling early are positively related. As expected, we show that early deals increase as the cost of absorptive capacity relative to the number of startups shrinks, and when there are fewer late stage buyers.

We also find some less expected results. When startups have to commit, they tend to sell too late relative to the decision that would maximize value creation. The intuition for this finding is that the gap between value creation (social) and value capture (private) is larger when the number of buyers is small. Since the late market has more potential buyers than the early market because absorptive capacity requires investment, startups exit inefficiently late despite considerable execution risks. An important implication of this result is that the availability of resources, such as venture capital, to enhance startups' execution paradoxically may exacerbate the situation by reducing early deals more than is desirable in terms of value creation.

If we compare different types of innovation, we find that the relationship between the degree of radicalness (which we model as startups with higher idiosyncratic uncertainty about their market value) and the timing of startup sale is more complex than the literature would suggest. Greater uncertainty, which is typically associated with more radical innovation, complicates negotiation over the terms of the deal (Jeong and Lee, 2015), increases the risk of misappropriation (Luo, 2014) and biases valuation of the invention (Allain et al., 2016). Thus, deals may be delayed to allow for the resolution of uncertainty. ${ }^{10}$ In our model, there are neither cognitive biases nor agency problems. Instead, in a context of radical innovation, startups prefer to delay the deal because the marginal increase in the value created will be greater with more buyers. However, buyers have greater incentives to invest in absorptive capacity, which

avoid investing in capabilities that are not valuable to acquirers such as, for instance, marketing and regulatory affairs. A late acquisition, on the other hand, can be treated by the buyer as a "stand alone" business needing little or no integration.

${ }^{9}$ Early vs. late becomes a strategic choice also if a significant amount of external finance is required. In this case, the startup has to decide whether to raise the money or not. By not raising the money, the startup de facto commits to going early. Conversely, if the startup does raise the money but sells early, the time and effort spent on raising money is of little value to the buyer.

${ }^{10}$ To the extent that the timing of an IPO can be equated to the timing of the startup's sale, Ferreira et al. (2014) show that firms engaged in more exploratory innovation, find it optimal to delay their IPO decision. 
makes the early market more attractive for startups. The second effect dominates if the cost of absorptive capacity relative to the number of startups is small, and if there are fewer late stage buyers. In this case, radical inventions are likely to be acquired early rather than late.

We next analyze the opposite case where startups observe the offers from early buyers, and decide whether to sell early or to wait for the late market. Somewhat counter-intuitively, this results in startups accepting too many early offers relative to what would maximize value creation, while too many incumbents invest in absorptive capacity which compounds the problem. The intuition is that the seller and the highest bidding buyer enter into an early deal only if it yields a higher value than the one they expect to capture in the late market. However, they consider only their own payoffs in the late market, not the payoffs of the other potential buyers. Venture capital, in this case, plays a positive role by reducing the number of inefficiently early deals, thereby shrinking the efficiency gap between value creation and value capture.

The paper is organized as follows. Section 2 summarizes the contribution of our paper vis-à-vis existing work. Section 3 describes the baseline model, and Section 4 presents our main findings. Section 5 discusses some extensions to this analysis, and Section 6 summarizes our results and concludes. Omitted proofs of the formal propositions are provided in the Appendix.

\section{Background literature}

Our paper contributes to the literature on markets for technology (Arora et al., 2001; Gans and Stern, 2003) and on high-tech entrepreneurship and entrepreneurial exit strategies (Baumol, 2010; Wennberg et al., 2010). Compared to existing work on markets for technology, our paper offers three novel elements. First, we analyze the timing of technology transactions, an important but understudied aspect of the division of innovative labor. Second, we build a parsimonious model of the equilibrium between early buyers and sellers. The two sides of technology markets have been studied mostly in isolation (Arora and Gambardella, 2010; Gans and Stern, 2010; Laursen et al., 2010). In our model, sellers face a tradeoff between the likelihood of execution failure and better future matches, and buyers choose whether to invest in absorptive capacity so they can also participate in the early market. Analyzing demand and supply together provides insights and conclusions not possible with extant approaches. Finally, we investigate how the market outcomes differ from the value maximizing outcomes.

Our analysis can be interpreted as reflecting the sale of an innovation. Only a handful of papers explicitly study the timing of technology transactions. Luo (2014) develops a model where early sales (of ideas) face greater information asymmetry and enjoy weaker intellectual property rights (IPR) protection since final products are better protected than mere ideas. She finds that both the best and the worst ideas are 
sold later, but for two different reasons. The seller captures a larger share in the late market where expropriation risk is muted, and therefore, prefers to wait if the idea is high-quality. Lower quality ideas cannot be sold in the early market because the buyer prefers to delay its development investment until more information about the true value of the idea is revealed. Our model does not rely on asymmetric information between sellers and buyers, and takes a market rather than a transaction cost perspective. In particular, we model the decisions of both buyers and sellers to enter the early market.

Ransbotham and Mitra (2010) assume that as time passes, more information is revealed to the market about the true value of the technology. For the seller of the technology, waiting for a late deal generates a tradeoff between increased integration problems with the buyer's established routines and resources which reduce the price, and reduced uncertainty which leads to a higher price because buyers compete more aggressively over targets. Our model captures a different tradeoff for startups: the possibility of a better match in the late market versus a greater likelihood of failure to reach a later stage. Furthermore, unlike Ransbotham and Mitra (2010), we derive the subgame perfect equilibrium of a model where both buyers and sellers decide whether to be active in the early market, and explore the efficiency properties of the market outcome.

Allain et al. (2016) study the way that the decision about the timing of technology licensing in the pharmaceutical industry depends on the number of buyers. They assume that sellers are overconfident about the quality of their technology, and delay licensing in the hope that additional (positive) information is revealed to the market. Delaying, however, is not costless from the point view of efficiency since the buyer's development costs are lower than those of the seller. Our paper suggests a different reason for selling late: Sellers capture more value in the late market where more buyers are present. In our model the number of early buyers and the likelihood of a startup selling early, are determined jointly in equilibrium, and delaying the sale can be efficient due to better matching in the late market.

Nörback and Persson (2009) build a model where a startup is either acquired early by an incumbent, or receives venture capitalist support and is sold late. Similar to Allain et al. (2016), they analyze competition among downstream firms. Thus, while the acquirer of the startup experiences a profit increase, other incumbents suffer a profit loss. The venture capitalist has a stronger incentive to develop the innovation because the price of the startup in the late market reflects both the profit increment for the acquiring firm and the reduction in the non-acquirers' profits. On the other hand, incumbents have an incentive to acquire the innovation early to preempt the over-investment in development. Nörback and Persson (2009) show that startups are sold in the late market only if venture capitalists have cost advantages relative to incumbent firms or if the development of the startup's idea is associated with double moral hazard problems. While their objective - of understanding how venture capital backing 
changes the incentives to innovate - differs from ours, we reach similar conclusions about how venture capital postpones the timing of startup sales.

Two other papers consider the timing of technology licensing and study how it depends on the features of the patent system. Gans et al. (2008) argue that licensing deals occur earlier if patent rights are more clearly defined, and they show empirically that there is an increase in the probability to license around the patent-grant date. Along similar lines, Hegde and Luo (2016) argue that mechanisms that make information about technology public, reduce the time-to-license of patented technology. They develop a model showing that when firms are forced to publish their patented applications, licensing is more likely even if the patent has yet to be granted. Taken together, these two papers show that if patent rights are better defined and there is more information available about the technology, technology transactions occur at an earlier stage.

To sum up, with the exception of Nörback and Persson (2009), in all of the abovementioned papers, the presence of asymmetric information and the fact that uncertainty tends to dissipate with time create incentives for startups to exit late. However, our paper assumes that information is symmetric and uncertainty persists. We introduce absorptive capacity as a (plausible) barrier to entry for buyers in the early market, and show that this generates a tradeoff for sellers between greater value creation and capture in the late market and lower execution risk in the early market. A novel feature of our analysis is that it highlights the importance of flexibility for the efficiency of the market for startups.

We should stress that our aim is not to dismiss the importance of asymmetric information and uncertainty in technology transactions but rather to offer a complementary set of reasons for the timing of the startup sale. Also, we ignore the potential agency conflict between entrepreneurs and investors and the varying motives of entrepreneurs, two issues which have been the focus of the finance and entrepreneurship literatures (e.g. Cumming and Mackintosh, 2003; Bayar and Chemmanur, 2011; Graebner et al., 2010).

\section{Baseline model}

We assume that the startup sale can occur at two points in time: early when the technology is nascent and needs further development (for instance, the startup has only a patent or a prototype), and late when the technology is already developed (for instance, the startup has a functioning technology or a product). ${ }^{11}$

\footnotetext{
${ }^{11}$ Technology transactions can take different forms. In some cases, arm's length contracts are enough to transfer both nascent and developed technologies. In other cases, technology is transferred through corporate acquisitions. In our model, a startup holds only one technology, and there is no difference between acquiring the technology through an exclusive licensing contract, or acquiring the firm.
} 
The key characteristics of early deals are: a) only buyers who have the absorptive capacity to evaluate and use the nascent technology participate; b) early acquisitions permit greater efficiency in scale-up.

We now describe each side of the market, and the decisions companies can make.

\section{Buyers or incumbent firms}

We assume that there is an exogenous number, $n$, of incumbent firms (buyers) that have no limit on the number startups they can acquire. This implies that buyers are not capacity constrained, and that the technologies they can acquire are not substitutes.

Buyers are always active in the late market where they acquire developed technologies, or more mature ventures. However, to participate in the early market, buyers need "absorptive capacity", i.e. the ability to understand, assimilate, develop and integrate nascent technology (Cohen and Levinthal, 1989). Absorptive capacity is the outcome of investments in basic research and scientific capabilities (Rosenberg, 1990) which we model as a fixed cost, $T .{ }^{12}$ We use $m$ to denote the number of buyers active in the early market. Buyers that have invested in absorptive capacity can acquire startups in both the early and the late markets. For simplicity, we assume that a startup acquired by an incumbent buyer is always successful. This assumption can be relaxed by allowing the probability of failure to be a constant fraction of the probability of failure if the startup was not acquired early.

\section{Sellers or startup firms}

We normalize the total number of startups to 1. Endogenous entry by startups in discussed in session 5.6. Startups can either sell in the early market (i.e. "go early") or "wait" for a late deal. If they sell in the early market, potential buyers will be firms that have invested in basic research, and therefore, are able to integrate and develop nascent technology. If the startup waits, buyers will compete for its technology in the late market.

Startup $j$ has a success probability $\theta_{j}$ of transitioning from the early to the late market which, abusing notation, we refer to simply as $\theta$. Thus, $1-\theta$ is a measure of the startup's execution disadvantage relative to an incumbent. Startups are heterogeneous in their ability to make the transition from a nascent to a developed technology, i.e. they differ in their execution (recruiting, manufacturing, sales, marketing) capability, which we assume independent of the quality of the underlying technology.

\footnotetext{
${ }^{12}$ Investing in basic research and scientific capability allows the generation of invention internally. Given our assumptions of the unlimited capacity of buyers and non-substitute technologies, the benefits from internally developed technologies can be modeled as a reduction in $T$.
} 
All startups draw a success probability from the same distribution function $Q($.), and their draws are public knowledge. For tractability, $Q($.) is assumed to be the uniform distribution over $[b, 1]$, where $1>b$ $\geq 0$.

Exit strategy

Entrepreneurs exit through their acquisition by an incumbent firm. We analyze two polar cases. In one, startups have to commit to going either early or late. If the startup goes early but is not acquired, it must exit the market. For a startup, finding an early buyer can divert the focus from developing the business. Entrepreneurs have many demands on their time: The technology has to be developed, engineers and team members recruited, and customers wooed. Looking for potential acquirers during this early phase of the startup lifecycle can be a distraction. Moreover, some of the investments made to develop the business may not be of value to early acquirers. These costs are likely to depend upon the industry and the technology, and other features of the environment. An alternative explanation for the need for commitment is weak protection of early stage ideas (Luo, 2014). Interaction with potential buyers may result in information leakages that undermine the value of the startup in the late market. The other case is where the startup can costlessly obtain offers from all the early buyers, and then can decide whether to accept one, or to reject all and continue to develop the business and opt for the late market. ${ }^{13}$

The value of a startup

Consider the case where startups have to commit to selling in either the early or the late market (the case without commitment is analyzed in section 4.2). In the late market, a startup's value to buyer $i$ is $w+v_{i}$ where $w$ is a common component, and $v_{i}$ is an idiosyncratic component. In the early market, buyers bid anticipating the value of the startup's technology once fully developed. Since we ignore discounting, the value to buyer $i$ in the early market is also $\mathrm{w}+v_{\mathrm{i}}$. Again, abusing notation, we drop the subindex henceforth. The common component represents the part of the value of the technology on which all buyers agree and which is known by all buyers, an assumption that we relax in section 5.2. The idiosyncratic component is buyer-specific. It represents heterogeneity in the value of the technology, and the specific fit with the buyer's existing products and capabilities. For instance, buyers might be heterogeneous in terms of geographic markets, distribution channels, potential for cannibalization of existing products, breadth of application of the innovation, etc. All buyers draw the idiosyncratic component from a distribution function $H($.$) . For tractability, we sometimes assume that H($.$) is uniform$

\footnotetext{
${ }^{13}$ Participating in an IPO or remaining independent are alternative startup exit routes. In the context of our model, these alternatives can be considered an outside option for startups selling in the late market.
} 
on $[-a,+a]$, so that $v_{i}$ is mean zero, and its variance increases with $a$. As we explain below, the variance of the idiosyncratic component can be related to the degree of radicalness or novelty of the technology.

\section{Early and late markets}

We model the functioning of the technology market as a sealed-bid second price auction (or Vickrey auction) where bidders (or buyers) submit bids without knowing those of the other bidders. The buyer submitting the highest bid ultimately acquires the startup paying the second-highest bid. Auctions provide a convenient micro-foundation for modeling price formation in startup sales (see, for instance, Ransbotham and Mitra, 2010; Nörback and Persson, 2009; Allain et al., 2016). We use a sealed-bid second price auction because it mimics a bidding competition among buyers for a target startup in which all potential buyers drop out except the final acquirer, a situation common in technology-based industries. However, our results do not rely on this specific modeling choice. They would hold in any situation in which the startup is assigned to the buyer with the highest valuation (in the given market) and the seller's share of the surplus is increasing in the number of buyers.

\section{Timing}

We assume that actions and decisions follow a four-stage game (see table 1). In stage I, incumbents decide whether to invest in absorptive capacity to allow them to be active in the early market. In stage II, startups discover their type, $\theta$, and in the commitment case, choose between the early and late markets. If startups are flexible, they do not have to make this choice before they observe all the early offers. In stage III, startups in the early market receive bids from those $m$ buyers that have invested in absorptive capacity. Profits are realized for those startups that have committed to going early, while in the flexible case, profits are realized if a bid is accepted by the startup. In stage IV, the startups that chose the late market and survived, receive bids from all $n$ buyers, and profits are realized. 
Table 1: Timing of the game for the two cases

\begin{tabular}{|l|l|l|l|}
\hline \multicolumn{4}{|c|}{ Case 1: commitment $\rightarrow$ strategic choice between early and late } \\
\hline \multicolumn{1}{|c|}{ Stage I } & \multicolumn{1}{|c|}{ Stage II } & \multicolumn{1}{c|}{ Stage III } & Stage IV \\
\hline $\begin{array}{l}\text { Incumbents decide } \\
\text { about investing in } \\
\text { absorptive capacity }\end{array}$ & $\begin{array}{l}\text { Startups decide about } \\
\text { going early versus } \\
\text { going late }\end{array}$ & $\begin{array}{l}\text { Profits are realized in } \\
\text { the early market for all } \\
\text { startups going early }\end{array}$ & $\begin{array}{l}\text { Surviving startups are } \\
\text { sold in the late market }\end{array}$ \\
\hline \multicolumn{3}{|c|}{ Case 2: flexibility $\rightarrow$ tactical choice between early and late } \\
\hline $\begin{array}{l}\text { Stage I } \\
\text { Incumbents decide } \\
\text { about investing in } \\
\text { absorptive capacity }\end{array}$ & Stage II & \multicolumn{1}{c|}{ Stage III } & Stage IV \\
\hline
\end{tabular}

\section{Solving the model}

It is useful to introduce some additional notation and results from the theory of order statistics. Buyer $i$ 's valuation of startup $j$ has the form $w+v$, and all $z$ buyers draw the idiosyncratic component from the distribution $H\left(\right.$.). Let $x(k, z)$ represent the $k^{\text {th }}$ highest out of $z$ idiosyncratic components. Then, $x(1, z)$ represents the highest idiosyncratic component, and $x(2, z)$ the second highest. Denote by $X(k, z)$ the expectation of $x(k, z)$.

Lemma 1. The cumulative distribution functions of the idiosyncratic component of the highest and the second highest valuation with $z$ buyers are respectively:

$F(x, z)=H(x)^{z}$ and

$G(x, z)=z H(x)^{z-1}-(z-1) H(x)^{z}$.

Proof: Application of Theorem 5.3.1 in Arnold et al. (1992: 111).

Lemma $2 \cdot \frac{1}{z}[X(1, z)-X(2, z)]=[X(1, z)-X(1, z-1)]$

Proof: By application of Lemma 1.

Lemma 3. Let $H(v) \sim U(-a,+a)$. Then, $X(1, z)=a \frac{z-1}{z+1}, X(2, z)=a \frac{z-3}{z+1}, \frac{1}{z}[X(1, z)-X(2, z)]=\frac{2 a}{z(z+1)}$.

Proof: By direct substitution. 


\subsection{Case 1: Exit timing is a strategic choice (commitment)}

In a sealed-bid second price auction, the dominant strategy for a buyer is to bid up to the true valuation; see, e.g. Dutta (1999). Hence, the expected price is equal to the expected value of the second-highest valuation. Because there are no transaction costs, this corresponds also to the seller's expected profit.

A buyer wins the auction if it draws the highest idiosyncratic component. Due to symmetry, this happens with probability $1 / z$. It pays a price equal to the second highest bid, yielding a profit of $x(1, z)-x(2, z)$. Thus, using the above notation, buyer's and seller's expected profits are:

$$
\begin{aligned}
\pi_{B}^{E}(m) & =\frac{1}{m}[X(1, m)-X(2, m)] & \pi_{S}^{E}(m) & =w+X(2, m) \\
\pi_{B}^{L}(n) & =\frac{1}{n}[X(1, n)-X(2, n)] & \pi_{S}^{E}(n) & =w+X(2, n)
\end{aligned}
$$

where E denotes the early market, L the late market, S the seller (startup) and B the buyer (incumbent). In this case, startups have to commit to an exit strategy. Since the exit choice is made before observing the potential bids in the early market, it is based on the expected profits in the two markets (stage III and stage IV of the game). Consider startup $j$. Denote the threshold value of $\theta$ such that the startup is indifferent between selling early and late by $\tilde{\theta}$. Then, $\tilde{\theta}$ is characterized by:

$$
\pi_{S}^{E}(m)=\tilde{\theta} \pi_{S}^{L}(n)
$$

In stage II, startup $j$ decides to sell early if $\theta \leq \tilde{\theta}$ and late if $\theta>\tilde{\theta}$.

Notice that the expected profit of the startup is increasing in the number of buyers, in both the early and the late markets. Thus, while an early acquisition increases value because of reduced execution errors, it might lead to a lower price for the startup because of the smaller number of potential buyers in the early market. (Indeed, if $m>n$, all startups would choose to sell in the early market and $\tilde{\theta}=1$.)

We can now consider stage I of the game and look at buyers' investment decisions in absorptive capacity. Notice that, because we have assumed unlimited acquisition capacity, all buyers are active in the late market. The decision to enter the early market is independent of the profit that a buyer makes in the late market. The expected number of startups sold early is $\mathrm{s}_{\mathrm{E}}=Q(\tilde{\theta})$. Buyers enter the early market until the expected profit from entry is equal to the cost of absorptive capacity. Ignoring integer constraints, the number of incumbents $m$ investing in absorptive capacity and participating in the early market is given by:

$$
Q(\tilde{\theta}) \pi_{B}^{E}(m)=T
$$

Assuming that $\theta$ and $v$ are uniformly distributed, we can rewrite equations (2) and (3). The indifferent type $\tilde{\theta}$ as a function of $m^{*}$ is given by: 


$$
\tilde{\theta}\left(m^{*}\right)=\frac{w+a \frac{m^{*}-3}{m^{*}+1}}{w+a \frac{n-3}{n+1}}
$$

The number of early buyers $m^{*}$ as a function of $\tilde{\theta}$ is:

$$
m^{*}(\tilde{\theta})=\frac{1}{2}\left(\sqrt{1+\frac{8 a(\tilde{\theta}-\mathrm{b})}{T(1-b)}}-1\right)
$$

Figure 2 provides a graphical representation of the equilibrium in $\theta$ and $m .{ }^{14} \mathrm{We}$ assume in what follows that the parameters of the model are such that there are equilibria with an active early market, and we focus here on the stable equilibrium. It should be noted that an equilibrium with no early market always exists. If a buyer expects other buyers not to invest in absorptive capacity, it has no incentive to invest itself because two or more competing buyers are needed to attract startups to the early market.

Figure 2: Stable and unstable equilibri

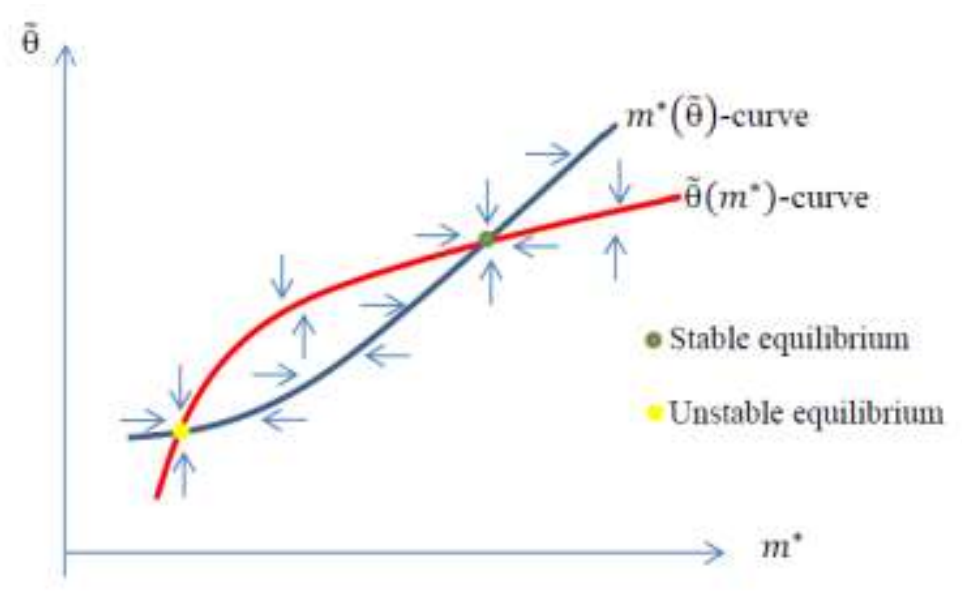

Table 2 summarizes the comparative statics with respect to the exogenous parameters of the model at the stable equilibrium.

${ }^{14}$ Both curves $\tilde{\theta}\left(m^{*}\right)$ and $m^{*}(\tilde{\theta})$ are positively sloped, $\left.\frac{d \widetilde{\theta}}{d m^{*}}\right|_{\tilde{\theta}\left(m^{*}\right)-\text { curve }}>0$ and $\left.\frac{d m^{*}}{d \widetilde{\theta}}\right|_{m^{*}(\tilde{\theta})-\text { curve }}>0$. Drawn in $\left(\tilde{\theta}, m^{*}\right)$-space, the $\tilde{\theta}\left(m^{*}\right)$-curve is concave, and the $m^{*}(\tilde{\theta})$-curve is convex. Stability requires that the $m^{*}(\tilde{\theta})$-curve is steeper than the $\tilde{\theta}\left(m^{*}\right)$-curve at the intersection, $\frac{T(1-b)\left(2 m^{*}+1\right)}{2 a}>\frac{\frac{4 a}{\left(m^{*}+1\right)^{2}}}{w+a \frac{n-3}{n+1}}$. 
Table 2: Comparative statics (positive increment in the parameter)

\begin{tabular}{|c|c|c|c|c|}
\hline Parameter & Economic interpretation & Channel & $\begin{array}{c}\text { Effect on the } \\
\text { number of firms } \\
\text { investing in AC }\end{array}$ & $\begin{array}{c}\text { Effect on the } \\
\text { timing decision of } \\
\text { startups }\end{array}$ \\
\hline$n$ & $\begin{array}{c}\text { Total number of late } \\
\text { buyers }\end{array}$ & $\begin{array}{c}\tilde{\theta}\left(m^{*}\right) \text {-curve: } \\
\tilde{\theta} \downarrow \rightarrow m^{*} \downarrow\end{array}$ & Reduction & Go late \\
\hline $\mathrm{T}$ & $\begin{array}{c}\text { Cost of investment in } \\
\text { AC }\end{array}$ & $\begin{array}{c}m^{*}(\tilde{\theta}) \text {-curve: } m^{*} \downarrow \\
\rightarrow \tilde{\theta} \downarrow\end{array}$ & Reduction & Go late \\
\hline$w$ & $\begin{array}{c}\text { Common component of } \\
\text { buyers' evaluations }\end{array}$ & $\begin{array}{c}\tilde{\theta}\left(m^{*}\right) \text {-curve: } \\
\tilde{\theta} \uparrow \rightarrow m^{*} \uparrow\end{array}$ & Increment & Go early \\
\hline$b$ & Availability of VC & $m^{*}(\tilde{\theta})$-curve: & Reduction & Go late \\
& $\begin{array}{c}m^{*} \downarrow \rightarrow \tilde{\theta} \downarrow \\
\end{array}$ & & \\
\hline
\end{tabular}

Most of these comparative statics are straightforward. A reduction in the cost of investment in absorptive capacity makes entry in the early market cheaper for incumbents, and thus, makes going early more attractive for the startups. A larger number of incumbents makes the late market more attractive for startups since they might expect to capture more value by selling in a thicker market. Thus, entry downstream (i.e. an increase in $n$ ) is associated with lower investment in absorptive capacity. By contrast, consolidation leads to more investment in absorptive capacity, and more early deals. A larger common component makes the expected profit of the startup less sensitive to the number of buyers, and thus, tilts its choice toward the early market, which avoids execution errors. The comparative statics with respect to the idiosyncratic component which proxies for the degree of radicalness of the invention, is less straightforward, and is analyzed in subsection 5.1. We can summarize this discussion in the following proposition:

Proposition 1: The number of incumbents investing in absorptive capacity, and the number of startups sold in the early market, increase if the cost of investment in absorptive capacity declines, the total number of buyers declines, execution failure increases and the invention has a larger common value.

Proof: By noticing that both curves in Figure 1 are positively sloped and that each of these changes either affects only one curve or affects both curves in the same direction.

An interesting result is the changes in execution failure. As we discuss below, greater availability of venture capital leads to a reduction in execution failure, or equivalently, to an increase in the probability 
of reaching the late stage. Therefore, we can model the availability of venture capital by an increase in $b$ (see, for instance, Nörback and Persson, 2009). Greater availability of venture capital has the direct effect of thinning the early market (more startups choose to go late). In response, fewer prospective buyers invest in absorptive capacity, further reducing the proportion of early sales. More generally, any policy that favors startup survival to the later stage can be reinterpreted as an increase in $b{ }^{15}$

\subsubsection{Value creation vs. value capture}

In this section, we study whether startups go too early or too late in relation to value creation, and whether too few or too many incumbents invest in absorptive capacity. We start by examining startups and what division between early and late markets would lead to the highest level of value creation. This requires comparing expected value creation in the early and late markets. It is straightforward to show that value creation is highest if startups with $\theta \leq \hat{\theta}$ go early, and startups with $\theta>\hat{\theta}$ go late, where:

$$
\hat{\theta}=\frac{w+X(1, m)}{w+X(1, n)}
$$

Startups care about value capture, and thus, the price they can secure in the early and late markets which would correspond to the second highest valuation, rather than about total value creation. The following lemma is useful.

Lemma 4. Let $H(v) \sim U(-a,+a)$. The ratio between value creation (highest valuation) and value capture (second highest valuation) shrinks with the number of buyers, $\frac{\partial \frac{w+X(1, z)}{w+X(2, z)}}{\partial z}<0$.

Lemma 4 implies that in thicker markets for startups not only is value creation greater because of a better matching but also the seller captures a larger share of the value created. We can now derive the key proposition of this section that when startups are forced to make strategic choices between going early versus going late, they systematically go too late.

\section{Proposition 2:}

(i) The equilibrium number of early buyers maximizes value creation conditional on the expected number of startups in the early market.

(ii) Startups tend to sell inefficiently late: The efficient threshold for staying in the early market, $\widehat{\boldsymbol{\theta}}$, is greater than $\widetilde{\boldsymbol{\theta}}$, the threshold used by startups in equilibrium.

\footnotetext{
${ }^{15}$ Alternatively, startup location in a cluster might increase survival chances, thus corresponding to a larger $b$. Indeed, Delgado et al. (2016) show that companies located in clusters tend to be more resilient to downturns. Provided they have a valuable business proposition, startups located in a cluster have easier access to complementary resources which reduces startup mortality in the transition from invention to innovation.
} 
(iii) Since there are too few startups selling early (relative to the value maximization level), the number of buyers that invest in absorptive capacity also is less than the number that maximizes value creation.

Proof: From Lemma $1, F(x, z)=H(x)^{z}$ is the distribution function for the highest value of the idiosyncratic component from z bidders, and $f(x, z)$ is the corresponding density function. A buyer's profit from entry into the early market is:

$$
Q(\tilde{\theta}) \int_{-a}^{a}\left(\int_{-a}^{v} f(x, m-1)(v-x) d x\right) h(v) d v-T
$$

The additional value created by an additional buyer is:

$$
Q(\hat{\theta}) \int_{-a}^{a}\left(\int_{-a}^{v} f(x, m-1)(v-x) d x\right) h(v) d v-T
$$

Hence, if $Q(\tilde{\theta})=Q(\hat{\theta})$, the equilibrium number of buyers in the early market maximizes value creation. This proves part (i) of the proposition. If $Q(\tilde{\theta})<Q(\hat{\theta})$, there are too few early buyers from the point of view of value creation. Next, we show that too few startups go early for a given number of early buyers, $m$. Notice that:

$$
\widehat{\boldsymbol{\theta}}>\widetilde{\boldsymbol{\theta}} \Leftrightarrow \frac{w+X(1, m)}{w+X(1, n)}>\frac{w+X(2, m)}{w+X(2, n)} \Leftrightarrow \frac{w+X(2, n)}{w+X(1, n)}>\frac{w+X(2, m)}{w+X(1, m)} .
$$

Using lemma 4 , this holds because $n>m$. Hence, we obtain $Q(\tilde{\theta})<Q(\hat{\theta})$ from which it follows immediately that in equilibrium there are too few early deals and too few early buyers.

Intuitively, the difference between value creation and value capture shrinks with the number of buyers. ${ }^{16}$ A startup compares value capture in the early and the late markets. If value capture were a constant fraction of value creation, the startup's decision would always coincide with the allocation that maximizes value creation. However, the share of the value captured by the seller is increasing in the number of potential buyers. Thus, startups inefficiently go too late because in the thin early market they capture a smaller fraction of the total value creation than in the thicker late market.

Below we analyze the conditions under which the difference between value creation allocations and value capture allocations is larger or smaller. We call the efficiency gap the ratio between $\widehat{\boldsymbol{\theta}}$ and $\widetilde{\boldsymbol{\theta}}$, that is:

$$
\text { Efficiency gap }=\frac{\widehat{\theta}}{\widetilde{\theta}}=\frac{\frac{w+X(1, m)}{w+X(1, n)}}{\frac{w+X(2, m)}{w+X(2, n)}} .
$$

Proposition 3. The efficiency gap declines with $m$, and increases with $n$.

\footnotetext{
${ }^{16}$ This result holds also for a variety of other distributions including the Generalized Extreme Value distribution and exponential.
} 
This proposition is interesting and helps identify a number of factors that might exacerbate the efficiency gap. Obviously, $m$ is endogenously determined by the incumbents' entry condition in the early market. However, because $m^{*}$ is conditionally efficient we can study the effects of all exogenous parameters that affect $m^{*}$ only through equation (2). Consider an increase in $T$, the cost of developing absorptive capacity for early acquisitions. Because a higher $T$ leads to a smaller $m^{*}$, i.e. in a thin early market, the tendency for startups to go too late is reinforced. This suggests that if the cost of performing basic research which typically is associated with absorptive capacity (Rosenberg, 1990; Arora and Gambardella, 1994) increases, not only do we have fewer early acquisitions but this also reduces the efficiency of the market for startups. We normalized the number of startups to 1 but we observe a similar effect if the number of startups declines. Thus, policies that stimulate the creation of startups through training or access to mentoring and expertise for instance, have the effect of increasing the number of active buyers in the early market, and thus of increasing value creation per startup.

Because $m^{*}$ depends, among other things, on the distribution of $\theta$, any shift in this distribution might increase or reduce the efficiency gap. Here, we focus on a factor that has received some attention in the innovation literature: the availability of venture capital. For a given supply of startups, we model an increase in the supply of venture capital as a shift in the distribution of $\theta$ to the right (first order stochastic dominance). This is consistent with the notion that venture capitalists help to develop the startup's organization, and reduce execution failure (Gompers and Lerner, 2001; Hsu, 2006). A shift in the distribution (an increase in $b$ ) increases the share of startups that go late. In turn, this implies that $m^{*}$ falls (see table 2). From Proposition 2 we can conclude that a greater availability of venture capital increases the efficiency gap, i.e. startups go inefficiently late, and especially in a condition of abundant venture capital. While venture capital has many benefits, a possible undesired effect of venture capital which our model identifies is that if they have to commit between going early versus going late, venture capital can cause excessive delays. This result contrasts with Hellmann and Veikko (2017) which shows that funding policies which presumably help to increase startups' survival chances, are effective for reducing inefficiencies due to dynamic interlinkages between generations of entrepreneurs which allow successful entrepreneurs to accumulate both expertise and wealth to support future generations of entrepreneurs. Another potential interpretation of a first order stochastic shift in the distribution of $\theta$ is related to the geographical location of the startup. If startups located in a cluster have a higher chance of survival then such startups may tend to go too late relative to maximizing value creation. Proposition 3 implies that this effect is reinforced if there are more potential buyers. Clusters cause this because close geographical proximity increases awareness of startup existence and technology which increases the number of potential buyers. On the other hand, a greater concentration of startups could incentivize buyers to invest 
in absorptive capacity, potentially offsetting the tendency for delay.

\subsection{Case 2: Exit timing is a tactical choice (flexibility)}

Here, we consider the case where the technology is well-protected, and the investments made are valuable to prospective buyers. Then, startups are flexible and can consider offers from buyers in the early market while also investing to scale-up for the late market. In this case, we need to examine when the startup is willing to accept a given bid in the early market rather than waiting to receive bids in the late market, and how the bidding strategies of buyers change in response. We assume that buyers active in both markets draw each time from the same distribution of idiosyncratic valuations which thus, are independent across markets. In section 5.5., we discuss the case of valuations that are the same across the two markets. Our qualitative findings do not change but the algebra is more cumbersome.

After observing its $\theta$, the startup will foresee that the expected profit in the late market is $\theta(w+X(2, n))$, and thus will accept any offer that is greater than the offers in the early market. We capture this by assuming that there is a reserve price $R^{*}(\theta)=\theta(w+X(2, n))$ in the second-price auction. ${ }^{17}$ This implies that the winning buyer pays $\operatorname{Max}\left\{w+x(2, m), R^{*}(\theta)\right\}$, where $x(2, m)$ is the second highest valuation among all the early buyers.

Buyers too take into account that they can buy in the late market if the startup is not sold in the early market, and this possibility modifies their bidding strategies. Lemma 5 characterizes the equilibrium bidding strategy of an early buyer.

Lemma 5. Define $\underline{v}^{*}(\theta)=\operatorname{Max}\left\{\theta\left(\pi_{B}^{L}(n)+w+X(2, n)\right)-w,-a\right\}$. Then, there exists a symmetric equilibrium in the early market where the bidding strategy of a buyer with idiosyncratic valuation $v$ is given by:

i) Bid its true valuation $(w+v)$ if $v \geq \underline{v}^{*}(\theta)$;

ii) Do not bid if $v<\underline{v}^{*}(\theta)$

Here, we provide the intuition for the case where $\underline{v}^{*}(\theta)=\theta\left(\pi_{B}^{L}(n)+w+X(2, n)\right)-w$. A buyer with a valuation equal to $w+\underline{v}^{*}(\theta)$ is indifferent between bidding and not bidding. The buyer can only make strictly positive profits if all other buyers have lower valuations. However, in this case, bidding $w+$ $\underline{v}^{*}(\theta)$, and paying the reserve price, or not bidding, and competing for the startup in the late market, yield

${ }^{17}$ This is a credible reserve price. In principle, startups could do even better by setting an optimal reserve price. However, any reserve price above $R^{*}(\theta)$ requires commitment on the seller's part: If the highest offer were below the optimal reserve price but above $R^{*}(\theta)$, it would be ex-post optimal to accept it. Since startups do not transact repeatedly with buyers, commitment is not plausible. 
the same expected profit equal to $\theta \pi_{B}^{L}(n)$. Consider now a buyer with a valuation greater than $w+\underline{v}^{*}(\theta)$. Two situations can arise: There are either competing buyers or not. If there are competing buyers, it is optimal to bid the true valuation in a second-price auction. If there are no competing buyers, it is also optimal to bid the true valuation and pay the reserve price, the lowest price at which the startup can be acquired.

A buyer's expected profit from its participation in the early market when bidding for a start-up of type $\theta$ is denoted $\Delta \pi_{B}^{E}(\theta)$ and is given by:

$$
\Delta \pi_{B}^{E}(\theta)=\int_{\underline{v}^{*}(\theta)}^{\mathrm{a}}(\underbrace{F\left(\underline{v}^{*}(\theta), m-1\right)\left(w+v-R^{*}(\theta)-\theta \pi t_{B}^{L}(n)\right)}_{\begin{array}{c}
\text { The highest valuation among the } \\
\text { competing buyers is less than or equal to } \underline{v}^{*}(\theta)
\end{array}}+\underbrace{\left.\int_{\underline{v}^{*}(\theta)}^{v} f(x, m-1)(v-x) d x\right)}_{\begin{array}{c}
\text { The highest valuation among the } \\
\text { competing buyers is above } \underline{v}^{*}(\theta)
\end{array}} h(v) d v
$$

A buyer acquires the startup and earns a strictly positive profit from its participation in the early market if (i) it has the highest valuation among the early buyers, and (ii) its valuation exceeds $\underline{v}^{*}(\theta) .{ }^{18}$ Integrating by parts, $\Delta \pi_{B}^{E}(\theta)$ can be written as:

$$
\Delta \pi_{B}^{E}(\theta)=\int_{\underline{v}^{*}(\theta)}^{a}\left(\int_{\underline{v}^{*}(\theta)}^{v} F(x, m-1) d x\right) h(v) d v .
$$

It follows immediately that $\Delta \pi_{B}^{E}(\theta)$ is decreasing in $m$ as $F(x, m-1)$ decreases in $m$. Integrating over the startups' set of types, the equilibrium number of buyers in the early market is given by the zero profit condition:

$$
\int_{b}^{1} \Delta \pi_{B}^{E}(\theta) q(\theta) d \theta-T=0
$$

Suppose that the cost of absorptive capacity $T$ is sufficiently low as to ensure a viable early market. Then, since $\Delta \pi_{B}^{E}(\theta)$ is decreasing in $m$, there exists a unique number of buyers $m^{*}$ which solves equation (7).

Proposition 4. When exit timing is a tactical choice, startups tend to sell inefficiently early, and the number of buyers that invest in absorptive capacity is also greater than the number that maximizes value creation.

While the formal proof is included in the Appendix, we provide the intuitive arguments underlying this proposition. From the standpoint of value creation, a startup should be traded in the early market if and only if the highest realized valuation $w+x(1, m)$ is greater than or equal to the expected value if the

\footnotetext{
${ }^{18}$ If there is only one early buyer with a valuation above $\underline{v}^{*}(\theta)$, its profit from participation in the early market is the profit earned in the early market, $w+v-R^{*}(\theta)$, minus the expected profit that it would have earned had it not been in the early market, $\theta \pi_{B}^{L}(n)$.
} 
startup continues to the late market, $\theta(w+X(1, n))$. However, Lemma 5 implies that the transaction takes place in the early market if and only if the highest valuation is greater than $w+\underline{v}^{*}(\theta)$. Since $\theta(w+X(1, n))>w+\underline{v}^{*}(\theta)$, it follows that too many deals take place in the early market for a given number of early buyers. This in turn, attracts too many buyers to the early market.

Intuitively, there is too much early trade because the trading parties consider only their own payoffs when evaluating an early deal. By setting a reserve price, the seller ensures for itself at least the expected profit in the late market, and the buyer bids only if the profit from winning the auction is greater than the expected profit in the late market. The outcome is that the buyer with the highest valuation trades with the seller if and only if their joint profit is greater than the expected joint profit in the late market. Therefore, they ignore the expected profits that accrue to other buyers if the startup were to continue to the late market, i.e. early deals generate a negative externality on the expected profits of other potential late buyers that is not accounted for. From the point of view of value creation, there are thus too many early deals.

Corollary 1. The number of early deals and the number of buyers investing in absorptive capacity are value maximizing when $n \rightarrow \infty$.

As the number of late buyers becomes very large, the profit in the late market goes to zero. Therefore, the negative externality that an early buyer's acquisition of a startup imposes on the potential late buyers disappears, and the market outcome is efficient.

\subsection{Discussion}

Taken together, Propositions 2 and 4 show that flexibility is pivotal to the efficiency properties of the market for startups: If startups have to commit to an exit strategy, early markets are too thin. In contrast, if startups can enter the early market, collect offers, and then decide on the timing, early markets are too thick. To our knowledge, this is a novel result, and has some important implications for policy, exemplified by the opposing effects of venture capital.

The intuition behind this important finding is twofold. In the case of commitment, startups tend to sell too late because the late market offers better value capture. In the case of flexibility, the option of selling late increases the value that the startup can capture in the early market. This reduces the incentive for the startup to wait, and there is early trade if buyer and seller have higher payoffs than in the late market. Since the expected payoffs of other potential buyers in the late market are not considered, there is too much early trade from the point of view of value creation. 


\section{Extensions}

\subsection{Degree of radicalness}

Radical inventions have more unpredictable outcomes since the path to a marketable product is longer, is characterized by various hazards and typically requires the orchestration of different complementary resources. Radical inventions are both more likely to fail and more likely to lead to a blockbuster innovation.

A natural way to model the degree of radicalness, as in Ransbotham and Mitra (2010), is through $a$ which parameterizes the variance of the idiosyncratic component. To preview our most interesting finding (see below), consider that the conventional wisdom among innovation scholars is that more radical inventions are sold later. Greater uncertainty which typically is associated to more radical inventions, complicates the negotiations around the terms of the deal (Jeong and Lee, 2015), and increases the risk of misappropriation (Luo, 2014) and the chances of biases in assessments of the value of the invention (Allain et al., 2016). As a result, both sellers and buyers might find it profitable to wait for additional information. Put differently, radical innovations are more uncertain and deals are delayed in order till the uncertainty is sufficiently resolved.

Our model highlights a more complex relationship between the degree of radicalness and the timing of the technology sale. Under certain conditions, we show that greater radicalness makes early deals more, not less, likely. Specifically, an increase in radicalness has two effects that push in opposing directions. One effect is through the greater importance of the matching between buyer and seller which pushes startups to the late market which, in turn, has more potential buyers. The following proposition demonstrates this result formally.

Proposition 5. Let $\boldsymbol{H}(\boldsymbol{v}) \sim \boldsymbol{U}(-\boldsymbol{a},+\boldsymbol{a})$. The number of early deals decreases for a given $m$, in both the flexible and the commitment cases.

While this first effect conforms to the conventional wisdom, it should be noted this is a different mechanism from the ones previously identified. For instance, we do not assume that uncertainty is resolved with time (i.e. $a$ declines while $w$ increases), that uncertainty causes adverse selection problems, or that sellers or buyers have cognitive biases. Instead, the result is driven by value creation: As $a$ increases, value creation increases more in the late than in the early market.

In addition, there is a second effect. The second effect arises because an increase in radicalness makes an early deal more profitable for buyers since it reduces the competition by increasing the degree of heterogeneity in valuations. This effect tends to increase $m^{*}$, making the early market more attractive for 
startups. It is interesting that these two effects are general, and do not depend on any distributional assumptions.

Obviously, to investigate under what conditions one effect dominates the other, requires reliance on distributional assumptions. Also, the answer will depend on the model parameters. For example, if the number of buyers in the early market, $m^{*}$, is relatively close to the total number of buyers, $n$, a change in radicalness has a very limited effect on startups' decisions. Thus, the comparative statics are driven by the effect on the expected profit of the buyers in the early market. Because $n$ and $m^{*}$ are close when $n$ is relatively small and $T$ tends to zero, under these conditions, an increase in radicalness brings about more early deals. Thus, by considering both demand and supply in the market for startups, we find that greater radicalness can lead to more and not fewer startups acquired early, and more incumbents investing in absorptive capacity.

We also consider a variant of the model in which the startups in an industry are heterogeneous with respect to the radicalness of their technology. We assume that startup $j$ draws both a success probability $\theta_{j}$ and a technology radicalness $a_{j}$, and the timing of the sale depends on both these parameters. In this model, it is possible to compare the decisions of startups with more and less radical technologies for a given number of buyers in the early and late markets. Here, only the first effect is present, and startups with more radical technologies sell later which is consistent with the conventional wisdom outlined above.

\subsection{Uncertainty about the common value component}

In the main analysis, we assumed perfect information about the common value component $w$. However, it is plausible that the invention has a common value component that is not perfectly observable in the early market. Instead, buyers might receive different and imperfect signals about the common value component (e.g. Ransbotham and Mitra; 2010). In such a setup, the problem of the "winner's curse" arises. The buyer that draws the highest valuation and wins the auction knows that the other buyers are likely to have received lower value signals related to the common component. Therefore, if the buyer had submitted a bid equal to the value indicated by the signal received, it would be likely to pay more than the true value of the startup. In response, buyers shade their bids in equilibrium. A natural assumption in our framework is that more information about startups is available in the late market. Therefore, the issue of the winner's curse is less severe in the late market which results in higher bids and more value capture for startups in that market. Hence, we could have the same trade-off between execution failure and value capture for a constant number of buyers in the early and late markets. Put differently, introducing uncertainty about the common value component reinforces the trade-offs in the baseline model. 


\subsection{Competition among buyers}

In the above analysis, buyers do not face competition in the downstream market, although they compete with each other over acquiring startups. That is, a buyer's valuation is independent of the number and identities of other buyers. However, if several firms are active in the same market segment, the benefits they derive from acquiring a technology are likely to depend on the intensity of the competition among them. Below, we try to accommodate competition in the simplest possible way in order to understand how it affects our results.

Following Allain et al. (2016), consider a product market with $n$ buyers and one startup available for sale. For simplicity, we focus on the case in which exit timing is a strategic choice (case 1). Before the acquisition, buyers are symmetric and earn profits equal to $t_{0}(n), t_{0}(n)>0$. If buyer $i$ acquires the startup it makes a profit $t_{l}(n)$ in the current market and profits $v_{i}$ in other unrelated markets. If another buyer acquires the startup, buyer $i$ 's profits are $t_{-1}(n)$, where $t_{-1}(n)<t_{0}(n)<t_{1}(n)$. This implies that buyer $i$ 's valuation of the startup is $w(n)+v_{i}$, where $w(n)=t_{l}(n)-t_{-1}(n)$. Using the comparative statics in table 2 , we know that a decline in $w(n)$ increases the probability of a late deal, and thus, reduces the number of buyers investing in absorptive capacity. If $w(n)$ declines with $n$, as in several models of product market rivalry, increasing competition among buyers makes a late sale more likely. Conversely, consolidation, as occurred for example, in the pharmaceutical industry, increases the number of early sales.

\subsection{Startups can choose between commitment and flexibility}

We analyzed two opposite cases for startups: 1) exit timing is a strategic choice that requires commitment, 2) exit timing is a tactical choice and the startup remains flexible. We considered these two cases as exogenously given to startups, possibly the outcome of industry characteristics. Here, we discuss the case where startups can choose between commitment and flexibility, and explore under what conditions one solution is preferred over the other.

Assume that startups can invest $F$ to gain intellectual property (IP) protection for their invention. If they do not invest in IP protection and are active in the early market, their invention becomes public knowledge, and thus, becomes worthless to buyers in the late market. Alternatively, the startup could hide the invention and solicit bids only in the late market. This is equivalent to exit timing being a strategic choice. However, if they invest $F$ they can be present in both markets without risk of expropriation. This is equivalent to exit timing being a tactical choice. In other words, $\mathrm{F}$ is the price of flexibility.

Flexibility provides the startup with two advantages. First, the startup can collect more offers since it can solicit bids in both the early and late markets. Second, flexibility allows the startup to establish a credible reserve price and improve rent-extraction in the early market auction. Both of these advantages depend on 
$\theta$, i.e. the probability that the startup survives to the late market. For low values of $\theta$, flexibility has almost no value as the startup will probably not make it to the late market, and its reserve price tends to zero. For $\theta$ close to 1 , the startup will only strike a deal in the early market if there is a very high bid, an event with a low probability. Thus, flexibility has little value because the startup typically will ultimately sell late. The (gross) payoff from flexibility is the largest for intermediate values of $\theta$. Startups with a high execution risk will sell early, and do not invest in IPR protection; startups with moderate execution risk will invest in IP protection and will receive bids in both markets; finally, startups with low execution risk will wait till the late market and will not invest in IPR protection.

\subsection{Buyers' valuations are constant over time}

In our analysis of the case where startups are flexible, we assumed that buyers draw independent valuations of the startup in each market. This might be the case if there is a long period between the early and late sales, and thus, the startup is a substantially different object. In other circumstances, it is more reasonable to assume that a given buyer's valuation of a given startup remains constant over time. Intuitively, because buyers' valuations are constant for the $m$ buyers active in the early market, both early buyers and startups use this information and the bids from the early auction to update their beliefs about the outcome of the auction in the late market. As a result, the optimal strategies of buyers and sellers are more complex.

Despite this greater complexity, the results are qualitatively similar. In equilibrium, startups are sold too early because when striking a deal neither early buyers no startups take into account the expected profits of late buyers. This is the same effect we observed in the previous analysis. Further, it can be proved that there is excessive buyer entry in the early market. In short, while introducing constant buyers' valuations makes the algebra more complicated, the results remain qualitatively similar. Details are available in the online appendix. In light of these findings, we speculate that in the more general case where late valuations are correlated but are not identical, the early valuations will yield similar results.

\subsection{Endogenous entry by startups}

So far, we have assumed that the supply of startups is fixed. However, the basic model could be extended by allowing the number of startups to be determined endogenously by a free entry condition (i.e. startups enter the industry as long as their expected profits are larger than their entry costs). In an earlier version of the paper, we analyzed a model in which the marginal entry costs increased with the number of startups that entered. This could reflect the scarcity of key resources needed to set up a technology company such as specialized labor, managerial talent and seed capital. Within this framework, entry by startups and by incumbents in the early market are mutually reinforcing: More startups make incumbents' entry into the 
early market more attractive, and vice-versa.

Turning to the efficiency properties of the equilibrium, when deciding about entry startups consider only their own profit, and disregard the profit of incumbents. This externality pushes insufficient entry by startups from the point of view of value creation. When the exit timing is a strategic choice (i.e. startups have to commit), we have shown that too few incumbents enter the early market for a given number of startups. Since both sides of the market have insufficient incentives to enter, there is unambiguously too little entry by startups in equilibrium. When the exit timing is a tactical choice, our analysis shows that there are too many incumbents in the early market for a given number of startups, inducing more entry by startups. In this case, there may be excessive or insufficient entry by startups in equilibrium, depending on the model parameters.

\section{Conclusions}

Many technology startups devise strategies for acquisition by large incumbents (Gans et al., 2002). In some cases, the acquisition is meant to take place at the idea stage, when the technology is nascent. In others, startups target a late acquisition by developing their innovation. The choice of startups of early versus late acquisition is interrelated to the decision of incumbents to develop the capabilities to evaluate and absorb nascent technologies. Thus, the timing of a startup-sale is influenced by the actions and characteristics of both seller and buyers, and depends on different environmental factors. An important novelty of our model compared to previous formal analyses of this issue is that we consider the interactions between sellers and buyers in both the early and the late market for startups. These interactions drive not just the value captured by each side but also the value created in the form of the fit between startup and acquirer.

A key determinant of the efficiency of the market for startups in terms of the timing of the acquisition is whether timing is a strategic choice for the startup, requiring commitment, or a tactical one, allowing flexibility. When startups are flexible, and after testing the early market can decide to pursue internal development (i.e. can choose to sell later), the early market sees too much activity. Too many startups accept early deals, and too many incumbents invest to participate in the early market.

On the other hand, when startups have to commit to developing their innovation internally (i.e. a late sale), too many choose to do so. Consistent with this, too few incumbents invest in absorptive capacity. Thus, if venture capital is abundant startups might inefficiently go late. This inefficiency arises through the reduced incentives of buyers to invest in the absorptive capacity required to participate in the early market, highlighting the value of adopting a market level perspective that aggregates the individual transaction level view common in the literature. Moreover, insofar as incumbents invest in research to 
acquire absorptive capacity, the rise in venture capital funded firms might in part explain the decline in corporate research (Arora et al., 2018). 


\section{REFERENCES}

Allain M.L., Henry E., Kyle M. 2016. Competition and the Efficiency of Markets for Technology. Management Science 62(4): 1000-1019

Arnold B.C., Balakrishnan N., Nagaraja H.N. 1992. A First Course in Order Statistics. Wiley, New York. Arora A., Gambardella A. 1994. Evaluating technological information and utilizing it: Scientific knowledge, technological capability, and external linkages in biotechnology. Journal of Economic Behavior and Organization 24(1): 91-114.

Arora A., Gambardella A. 2010. Ideas for Rent: An Overview of Markets for Technology. Industrial and Corporate Change 19: 775-803

Arora A., Fosfuri A., Gambardella A. 2001. Markets for Technology: The Economics of Innovation and Corporate Strategy. MIT Press: Cambridge, MA.

Arora A., Belenzon S., Rios L. 2014. Make, Buy, Organize: The interplay between R\&D, external knowledge sourcing and firm structure. Strategic Management Journal 35(3): 317-337.

Arora A., Belenzon S., Patacconi A. 2018. The decline of science in corporate R\&D. Strategic Management Journal 39(1): 3-32.

Arora, A., Cohen W.M., Walsh J.P. 2016. The acquisition and commercialization of invention in American manufacturing: Incidence and impact. Research Policy 45 (6): 1113-1128.

Åstebro, T., Serrano, C. 2015.Business Partners: Complementary Assets, Financing, and Invention Commercialization. Journal of Economics \& Management Strategy 24 (2): 228-252.

Baumol W.J. 2010. The Microtheory of Innovative Entrepreneurship. Princeton University Press: Princeton and Oxford.

Bayar O., Chemmanur T.J. 2011. IPOs versus Acquisitions and the Valuation Premium Puzzle: A Theory of Exit Choice by Entrepreneurs and Venture Capitalists. The Journal of Financial and Quantitative Analysis 46(6): 1755-1793.

Cohen W., Levinthal D. 1989. Innovation and Learning: The Two Faces of R \& D. The Economic Journal 99 (397): 569-596.

Cumming D.J., MacIntosh J.G. 2003. A cross-country comparison of full and partial venture capital exits. Journal of Banking \& Finance 27(3): 511-548.

Cunningham C. 2017. When does novelty pay. Unpublished manuscript. Duke University.

Delgado M., Porter M., Stern S. 2016. Clusters and the Great Recession. Unpublished manuscript. Cambridge, MA.

Dutta P.K. 1999. Strategies and Games: Theory and Practice. Cambridge: MIT Press. 
Ferreira D., Manso G., Silva A.C. 2014. Incentives to Innovate and the Decision to Go Public or Private. Review of Financial Studies 27(1): 256-300.

Gans J., Stern S. 2003. The Product Market and the 'Market for Ideas': Commercialization Strategies for Technology Entrepreneurs. Research Policy 32(2): 333-350.

Gans J., Stern S. 2010. Is there a market for ideas? Industrial and Corporate Change 19(3): 805-837.

Gans J., Hsu D., Stern S. 2008. The Impact of Uncertain Intellectual Property Rights on the Market for Ideas: Evidence for Patent Grant Delays. Management Science 54(5): 982-997.

Gans J., Hsu D., Stern S. 2002. When Does Start-Up Innovation Spur the Gale of Creative Destruction? RAND Journal of Economics 33(4): 571-586.

Gans J.S., Stern S., Wu J. 2016. Foundations of Entrepreneurial Strategy. Available at SSRN: https://ssrn.com/abstract=2844843 or http://dx.doi.org/10.2139/ssrn.2844843

Gompers, P. and Lerner, J. 2001. The Venture Capital Revolution. The Journal of Economic Perspectives 15(2): 145-168.

Graebner M.E., Eisenhardt K.M. 2004. The Seller's Side of the Story: Acquisition as Courtship and Governance as Syndicate in Entrepreneurial Firms. Administrative Science Quarterly 49(3): 366403.

Graebner M.E., Eisenhardt K.M., Roundy P. 2010. Success and Failure in Technology Acquisitions: Lessons for Buyers and Sellers. Academy of Management Perspectives 24(3): 73-92.

Guedj I., Scharfstein D. 2004. Organizational Scope and Investment: Evidence from the Drug Development Strategies and Performance of Biopharmaceutical Firms. NBER Working Paper No. 10933.

Hegde D., Luo H. 2016. Patent Publication and the Market for Ideas. Management Science. Forthcoming. Hellmann T.F., Veikko T. 2017. Fostering Entrepreneurship: Promoting Founding or Funding? Unpublished manuscript.

Hsu D. 2006. Venture Capitalists and Cooperative Start-up Commercialization Strategy. Management Science 52(2): 204-219.

Jeong S., Lee S. 2015. Strategic timing of academic commercialism: evidence from technology transfer. The Journal of Technology Transfer 40(6): 910-931.

Laursen K., Leone M.I., Torrisi S. 2010. Technological exploration through licensing: new insights from the licensee's point of view. Industrial and Corporate Change 19(3): 871-897.

Luo H. 2014. When to Sell Your Idea: Theory and Evidence from the Movie Industry. Management Science 60(12): 3067-3086.

Maine E., Thomas V.J. 2017. Raising financing through strategic timing. Nature Nanotechnology 12(2): 93-98. 
Mathisen M.T., Rasmussen E. 2016. Science-Based Entrepreneurial Firms as Real Options: Assessing the Outcomes of the Norwegian Firm Population from 1995 to 2012. Unpublished manuscript.

Nörback P.J., Persson L. 2009. The Organization of the Innovation Industry: Entrepreneurs, Venture Capitalists, and Oligopolists. Journal of the European Economic Association 7(6): 1261-90.

Ransbotham S., Mitra S. 2010. Target Age and the Acquisition of Innovation in High-Technology Industries. Management Science 56(11): 2076-2093.

Rosenberg N. 1990. Why do firms do basic research (with their own money)? Research Policy 19(2): 165-174.

Teece D. 1986. Profiting from technological innovation: Implications for integration, collaboration, licensing and public policy. Research Policy 15(6): 285-305.

Wennberg K., Wiklund J., DeTienne D.R., Cardon M.S. 2010. Reconceptualizing entrepreneurial exit: Divergent exit routes and their drivers. Journal of Business Venturing 25(4): 361-375. 


\section{APPENDIX}

\section{A. Proof of Lemma 4}

Notice that $\frac{\partial \frac{w+X(1, z)}{w+X(2, z)}}{\partial z}=\frac{\frac{\partial X(1, z)}{\partial z}[w+X(2, z)]-\frac{\partial X(2, z)}{\partial z}[w+X(1, z)]}{[w+X(2, z)]^{2}}<0$ if $\frac{\partial X(2, z)}{\partial z}>\frac{\partial X(1, z)}{\partial z}$. With a uniform distribution of the idiosyncratic component of buyers' evaluations $\frac{\partial X(2, z)}{\partial z}=a \frac{4}{[z+1]^{2}}>a \frac{2}{[z+1]^{2}}=\frac{\partial X(1, z)}{\partial z}$.

\section{B. Proof of Proposition 3}

We have that $\frac{\partial \widetilde{\hat{\theta}}}{\partial m}=\frac{\frac{\partial X(1, m)}{\partial \mathrm{m}} \widetilde{\theta}-\frac{\partial X(2, m)}{\partial \mathrm{m}} \theta^{*}}{(\widetilde{\theta})^{2}}<0$ because $\hat{\theta}>\tilde{\theta}$ and $\frac{\partial X(2, m)}{\partial \mathrm{m}}>\frac{\partial X(1, m)}{\partial \mathrm{m}}$. Furthermore, $\frac{\partial \frac{\widehat{\hat{\theta}}}{\partial n}}{\partial n}=$ $\frac{\frac{-\frac{\partial X(1, n)}{\partial \mathrm{n}}[w+X(1, m)]}{[w+X(1, n)]^{2}} \widetilde{\theta}+\frac{\frac{\partial X(2, n)}{\partial \mathrm{n}}[w+X(2, m)]}{[w+X(2, n)]^{2}} \widehat{\theta}}{(\widetilde{\theta})^{2}}=\frac{\frac{-\frac{\partial X(1, n)}{\partial \mathrm{n}}}{w+X(1, n)} \widetilde{\theta} \widehat{\theta}+\frac{\frac{\partial X(2, n)}{w+X(2, n)}}{w} \widetilde{\theta} \widehat{\theta}}{(\widetilde{\theta})^{2}}=\frac{\widehat{\theta}}{\widetilde{\theta}}\left[\frac{-\frac{\partial X(1, n)}{\partial \mathrm{n}}}{w+X(1, n)}+\frac{\frac{\partial X(2, n)}{\partial \mathrm{n}}}{w+X(2, n)}\right]>0$ because $w+$ $X(1, n)>w+X(2, n)$ and $\frac{\partial X(2, n)}{\partial \mathrm{n}}>\frac{\partial X(1, n)}{\partial \mathrm{n}}$.

\section{Proof of Lemma 6}

In the construction of the equilibrium, we assume that buyers with a valuation $v \geq R(\theta)$ follow a symmetric bidding strategy $b(v)$ where $\frac{\partial b(v)}{\partial v}>0$. Also, it is assumed at this point that $\theta\left(\pi_{B}^{L}(n)+w+X(2, n)\right)-$ $w \geq-a$. A buyer of type $\underline{v}^{*}(\theta)$ bids $b\left(\underline{v}^{*}(\theta)\right)$ and wins only if all other buyers have valuations below $\underline{v}^{*}(\theta)$. Hence, whenever a buyer of type $\underline{v}^{*}(\theta)$ wins, it pays the reservation price $R(\theta)$. For a buyer of type $\underline{v}^{*}(\theta)$ the alternative to bidding $b\left(\underline{v}^{*}(\theta)\right)$ is to not bidding. If all other bidders have valuations below $\underline{v}^{*}(\theta)$, the expected profit from not bidding is $\theta \pi_{B}^{L}(n)$, because the startup is sold in the late market. In equilibrium, the marginal type $\underline{v}^{*}(\theta)$ has to be indifferent between bidding and not bidding:

$$
\begin{gathered}
F\left(\underline{v}^{*}(\theta), m-1\right)\left(\underline{v}^{*}(\theta)+w-R(\theta)\right)+\left(1-F\left(\underline{v}^{*}(\theta), m-1\right)\right) \times 0= \\
F\left(\underline{v}^{*}(\theta), m-1\right) \theta \pi_{B}^{L}(n)+F\left(\underline{v}^{*}(\theta), m-1\right) \times 0 \Leftrightarrow \\
\underline{v}^{*}(\theta)=\theta \pi_{B}^{L}(n)+R(\theta)-w=\theta\left(\pi_{B}^{L}(n)+w+X(2, n)\right)-w
\end{gathered}
$$

Consider now types $v>\underline{v}^{*}(\theta)$. Two situations can occur: There are either competing buyers or not. If there are competing buyers, it is optimal to bid the true valuation. The startup is sold in the early market because there is at least one other buyer that bids above $R(\theta)$, and it follows from standard second-price auction logic that bidding the true valuation is optimal. In the other case, without competing buyers, it is also optimal to bid the true valuation. The start-up is then bought at the price $R(\theta)$ which (i) results in higher 
profits than buying in the late market since $v>\underline{v}^{*}(\theta)$, and (ii) $R(\theta)$ is the lowest price at which the startup can be acquired.

If $\theta\left(\pi_{B}^{L}(n)+w+X(2, n)\right)-w<-a$, a similar argument establishes that it is optimal for a buyer to bid its valuation for all $v$, and hence $\underline{v}^{*}(\theta)=-a$ in this case.

\section{Proof of Proposition 4}

We show first that buyers over-invest in absorptive capacity. We then show that this behavior results in too many early deals from the point of view of value creation.

Claim 1: Buyers overinvest in absorptive capacity.

Suppose that a startup of type $\theta$ is sold in the early market for some $x(1, m) \geq \underline{\hat{v}}(\theta) \geq-a$. There is a reserve price $\hat{R}(\theta)$ in the auction representing the expected value creation in the late market. Then, applying the same steps as in the derivation of $\Delta \pi_{B}^{E}(\theta)$, the contribution of the marginal early buyer to value creation can be written as:

$$
\Delta V^{E}(\theta, m) \equiv \int_{\underline{\hat{v}}(\theta)}^{a}\left(F(\underline{\hat{v}}(\theta), m-1)(w+\underline{\hat{v}}(\theta)-\hat{R}(\theta))+\int_{\underline{\hat{v}}(\theta)}^{v} F(x, m-1) d x\right) h(v) d v .
$$

where $\underline{\hat{v}}(\theta)$ is the threshold value that maximizes value creation. The value created is maximized for $\partial \Delta V^{E}(\theta, m) /_{\partial \underline{\hat{v}}}=0 \Leftrightarrow \underline{\hat{v}}(\theta)=\hat{R}(\theta)-w$ if $-a<\hat{R}(\theta)-w$. Otherwise, $\underline{\hat{v}}(\theta)=-a$. As argued in the main text, the expected value creation in the late market is $\hat{R}(\theta)=\theta(w+X(1, n))$. Hence,

$$
\underline{\hat{v}}(\theta) \equiv \operatorname{Max}\{\theta(\mathrm{w}+V(1, n))-w,-a\} .
$$

Plugging $\underline{\hat{v}}(\theta)$ into $\Delta V^{E}(\theta, m)$, we obtain:

$$
\Delta V^{E}(\theta, m)=\int_{\underline{\hat{v}}(\theta)}^{a}\left(\int_{\underline{\hat{v}}(\theta)}^{v} F(x, m-1) d x\right) h(v) d v
$$

Finally, arguing as in the proof of Lemma 6, we can show that $\Delta V^{E}(\theta, m)$ is decreasing in $m$. Hence, the value maximizing the number of early buyers is determined by the following equation:

$$
\int_{b}^{1} \Delta V^{E}(\theta, m) q(\theta) d \theta-T=0
$$

Comparing equations (A2) and (6), and using $\underline{v}^{*}(\theta) \leq \underline{\hat{v}}(\theta)$, we obtain $\Delta V^{E}(\theta, m) \leq \Delta \pi_{B}^{E}(\theta, m)$.

Furthermore, $\Delta V^{E}(\theta, m)<\Delta \pi_{B}^{E}(\theta, m)$ for $\theta$ sufficiently large as $-a<\underline{v}^{*}(1)<\underline{\hat{v}}(1)$. Using equations (7) and (A3), this implies that $m^{*}>\widehat{m}$.

Claim 2: Too many early deals. 
The expected number of deals in the early market is given by $\int_{d}^{1}\left(1-F\left(\underline{v}^{*}(\theta), m^{*}\right)\right) q(\theta) d \theta$ which is greater than the number of the value maximizing number of deals $\int_{d}^{1}(1-F(\underline{\hat{v}}(\theta), \widehat{m}))$ since $\underline{v}^{*}(\theta) \leq \underline{\hat{v}}(\theta)$ and $m^{*}>\widehat{m}$.

\section{E. Proof of Corollary 1}

Using equations (A.1), (A.2), (6), and (7), we have that the market outcome is value maximizing in the limit for $n \rightarrow \infty$ since $\underline{\hat{v}}(\theta) \rightarrow \underline{v}^{*}(\theta)$ and $\widehat{\mathrm{R}}(\theta) \rightarrow R^{*}(\theta)$ for $n \rightarrow \infty$.

\section{F. Proof of Proposition 5.}

Consider first the case of commitment. The probability of a late sale is Prob(Late) $=1-\tilde{\theta}$. Since $\partial \tilde{\theta} / \partial a<0$ for given $m$, the proposition follows immediately in this case. Consider now the case of flexibility. The probability of a late sale can be rewritten as $\operatorname{Prob}($ Late $)=\int_{\underline{\theta}}^{1} F\left(\underline{v}^{*}(\theta)\right) q(\theta) d \theta$, where $\underline{\theta} \equiv(w-a) /(\pi(n)+w+X(2, n))=(w-a) /\left(\frac{2 a}{n(n+1)}+w+\frac{a(n-3)}{n+1}\right)$ is the lowest value of $\theta$ for which a late sale can be optimal. For $\boldsymbol{\theta}=\underline{\boldsymbol{\theta}}$, a late sale takes place if and only if $x(1, m)$ is equal to the lower-bound (i.e. $x(1, m)=-a$ ). For $\boldsymbol{\theta}<\underline{\boldsymbol{\theta}}$, the execution risk is so high that the startup is always sold early, no matter how unfavorable the valuations in the early market. We have:

$$
\frac{\partial \operatorname{Prob}(\text { Late })}{\partial \mathrm{a}}=-F\left(\underline{v}^{*}(\underline{\theta})\right) q(\underline{\theta}) \underline{\partial} \underline{\theta} / \partial a+\int_{\underline{\theta}}^{1} f\left(\underline{v}^{*}(\theta)\right) \underline{v}^{*}(\theta) / \partial a q(\theta) d \theta .
$$

Calculations show that $\underline{\partial \theta} / \partial a<0$. Furthermore, for $\theta \geq \underline{\theta}, \underline{v}^{*}(\theta) / \partial a=\theta\left(\frac{2}{n(n+1)}+\frac{(n-3)}{n+1}\right)>0$. Together, these imply that $\frac{\partial \operatorname{Prob}(\text { Late })}{\partial a}>0$. 